\title{
Titanium carbide MXene shows an electrochemical anomaly in water-in-salt electrolytes
}

Xuehang Wang, ${ }^{a}$ Tyler S. Mathis, ${ }^{a}$ Yangyunli Sun, ${ }^{b}$ Wan-Yu Tsai, ${ }^{c}$ Netanel Shpigel, ${ }^{d}$ Hui Shao, ${ }^{e}$ Danzhen Zhang, ${ }^{a}$ Kanit Hantanasirisakul, ${ }^{a}$ Fyodor Malchick, ${ }^{d, f}$ Nina Balke, ${ }^{g}$ De-en Jiang, ${ }^{b}$ Patrice Simon, ${ }^{e}$ Yury Gogotsi ${ }^{a}$ *

${ }^{a}$ A. J. Drexel Nanomaterials Institute, and Department of Materials Science and Engineering, Drexel University, Philadelphia, Pennsylvania 19104, USA.

${ }^{\mathrm{b}}$ Department of Chemistry, University of California, Riverside, California 92521, USA.

${ }^{c}$ Chemical Sciences Division, Oak Ridge National Laboratory, Oak Ridge, Tennessee 37831, USA.

${ }^{d}$ Department of Chemistry, Bar-Ilan University, Ramat-Gan 52900, Israel

${ }^{\mathrm{e}}$ Materials Science Department - CIRIMAT, Université Toulouse III Paul Sabatier, 118 route de Narbonne, 31062 Toulouse, France.

${ }^{\mathrm{f}}$ Center for physical and chemical methods of research and analysis, al-Farabi Kazakh National University, 050040 Almaty, Kazakhstan.

${ }^{g}$ Center for Nanophase Materials Sciences, Oak Ridge National Laboratory, Oak Ridge, Tennessee 37830, USA. 
KEYWORDS: Titanium carbide MXene, water-in-salt electrolytes, desolvation-free cation insertion, abnormal electrochemical behavior

ABSTRACT: Identifying and understanding charge storage mechanisms is important for advancing energy storage, especially when new materials and electrolytes are explored. Wellseparated peaks in cyclic voltammograms (CVs) are considered key indicators of diffusioncontrolled electrochemical processes with distinct Faradic charge transfer. Herein, we report on an electrochemical system with separated CV peaks, accompanied by surface-controlled partial charge transfer, in $2 \mathrm{D} \mathrm{Ti}_{3} \mathrm{C}_{2} \mathrm{~T}_{x}$ MXene in water-in-salt electrolytes. The process involves the insertion/desertion of desolvation-free cations, leading to an abrupt change of the interlayer spacing between MXene sheets. This unusual behavior increases charge storage at positive potentials, thereby increasing the amount of energy stored. This also demonstrates new opportunities for the development of high-rate aqueous energy storage devices and electrochemical actuators using safe and inexpensive aqueous electrolytes.

\section{TEXT}

Electrochemical energy storage is the key technology determining the future of transportation, mobile communication, and renewable energy utilization. ${ }^{1,2}$ Faradaic reduction-oxidation (redox) reactions and the electrostatic formation of electrical double-layers (EDLs) are used to store charge in batteries and EDL capacitors (EDLCs, or supercapacitors), respectively. More recently, materials that exhibit continuous surface redox reactions across a wide range of potentials, known as pseudocapacitive materials, have attracted attention as a way to increase the energy density of supercapacitors with minimal decreases in their power and cycle life. To distinguish between these charge storage mechanisms, electrochemists will primarily use the shape of cyclic voltammograms 
$(\mathrm{CVs}){ }^{3}$ EDL formation results in a rectangular $\mathrm{CV}$, where the amount of charge stored varies linearly as a function of potential. On the other hand, CVs with sharp peaks that have clear separation between the potentials of the oxidative and reductive reactions represent a diffusioncontrolled Faradaic, or battery-type, process. ${ }^{4}$ In the case of surface redox or intercalation pseudocapacitance, either an EDL-like rectangular CV, like in the case of $\mathrm{RuO}_{2}$ and $\mathrm{MnO}_{2}$, or a broad and electrochemically reversible redox wave with a minimal separation between oxidation and reduction peaks is overlaid on a capacitive envelope, e.g., for titanium carbide MXene in protic electrolytes. ${ }^{5,6}$ The CVs of pseudocapacitive materials may also have an expanded envelope within the potential range of the redox processes, like in $\mathrm{Nb}_{2} \mathrm{O}_{5}$ in $\mathrm{Li}$ based organic electrolytes ${ }^{7}$ or $\mathrm{Cl}$ terminated MXene in LP30 electrolyte. ${ }^{8}$

It is important to mention that in all these cases the charge storage mechanism depends not only on the electrode material, but also on the electrolyte used. ${ }^{9}$ Water-in-salt (WIS) electrolytes have attracted significant attention in recent years because of their ability to suppress hydrogen evolution and electrode oxidation, expand the voltage window, and enable high-voltage aqueous lithium-ion chemistries without use of flammable organic solvents. ${ }^{10}$ Two-dimensional (2D) transition metal carbides and nitrides (MXenes) have shown EDL-like charge storage in neutral electrolytes and surface redox storage in acidic electrolytes ${ }^{11}$, but the electrochemical behavior of MXenes in WIS electrolytes has not been deeply investigated yet, especially at the anodic potentials. Here we investigated $\mathrm{Ti}_{3} \mathrm{C}_{2} \mathrm{~T}_{x}$ (where $\mathrm{T}_{x}$ stands for surface terminations like $=\mathrm{O},-\mathrm{OH}$, $-\mathrm{Cl}$, and $-\mathrm{F}) \mathrm{MXene}$ with increased chemical stability produced using an improved synthesis process (Methods) in several WIS Li-ion electrolytes to reach the range of anodic potentials that was previously inaccessible for MXenes and determined the charge storage capabilities and mechanisms of $\mathrm{Ti}_{3} \mathrm{C}_{2} \mathrm{~T}_{x}$ in WIS electrolytes with wide voltage windows. 


\section{Activated electrochemical process}

Figure 1a shows CVs of a vacuum-filtered $\mathrm{Ti}_{3} \mathrm{C}_{2} \mathrm{~T}_{x}$ MXene film in $3 \mathrm{M} \mathrm{H}_{2} \mathrm{SO}_{4}$ and three WIS electrolytes, specifically $19.8 \mathrm{~m}$ (mol/kg water) lithium chloride (LiCl), $19.2 \mathrm{~m}$ lithium bromide (LiBr), and $15 \mathrm{~m}$ lithium bis(trifluoromethanesulfonyl)-imide (LiTFSI) aqueous electrolytes. $\mathrm{Ti}_{3} \mathrm{C}_{2} \mathrm{~T}_{x}$ is typically used as a negative electrode material in aqueous systems as $\mathrm{Ti}_{3} \mathrm{C}_{2} \mathrm{~T}_{x}$ is oxidized beyond 0.1-0.2 $\mathrm{V}$ vs $\mathrm{Ag} / \mathrm{AgCl}{ }^{12,13}$ When a WIS electrolyte is used, the stable electrochemical potential window for $\mathrm{Ti}_{3} \mathrm{C}_{2} \mathrm{~T}_{x}$ is extended to $0.7-0.9 \mathrm{~V} v s \mathrm{Ag}$ (an Ag reference electrode was used throughout this study, unless specifically stated). Notably, previous works reported that WIS electrolyte can expand the negative potentials window of MXene electrode. ${ }^{14,} 15$ Here, the maximum applicable potential, which is approximately $0.5 \mathrm{~V}$ above the open circuit potential (OCP), enables us to explore the electrochemical behavior of MXenes under positive potentials. The overall potential window for $\mathrm{Ti}_{3} \mathrm{C}_{2} \mathrm{~T}_{x}$ in each of the three WIS electrolytes is $1.6 \mathrm{~V}$, a $60 \%$ increase over the potential windows of $3 \mathrm{M} \mathrm{H}_{2} \mathrm{SO}_{4}$ and $1 \mathrm{M} \mathrm{LiCl}$ (Figure S1a).

The electrochemical charge/discharge processes for $\mathrm{Ti}_{3} \mathrm{C}_{2} \mathrm{~T}_{x}$ in the WIS electrolytes are highly reversible, as the Coulombic efficiencies of the CVs in Figure 1a are all above $99 \%$. Chronoamperometry tests demonstrate that the steady-state leakage current is miniscule $(0.0125$ A/g) until $0.8 \mathrm{~V}$ in $19.8 \mathrm{~m} \mathrm{LiCl}$ (Figure 1b), indicating that contributions from any side reactions are negligible and the oxidation resistance of $\mathrm{Ti}_{3} \mathrm{C}_{2} \mathrm{~T}_{x}$ is improved in the WIS electrolytes. X-ray diffraction (XRD) (Figure S2a), Raman spectroscopy (Figure S2b) and X-ray photoelectron spectroscopy (XPS) (Figure S3) all showed minor differences in the $\mathrm{Ti}_{3} \mathrm{C}_{2} \mathrm{~T}_{x}$ electrodes before and after 1,000 cycles in $19.8 \mathrm{~m} \mathrm{LiCl}$ with a $1.6 \mathrm{~V}$ potential window. Furthermore, the capacitance retention is $94 \%$ after 10,000 cycles in the $19.8 \mathrm{~m} \mathrm{LiCl}$ electrolyte (Figure S4). 
a
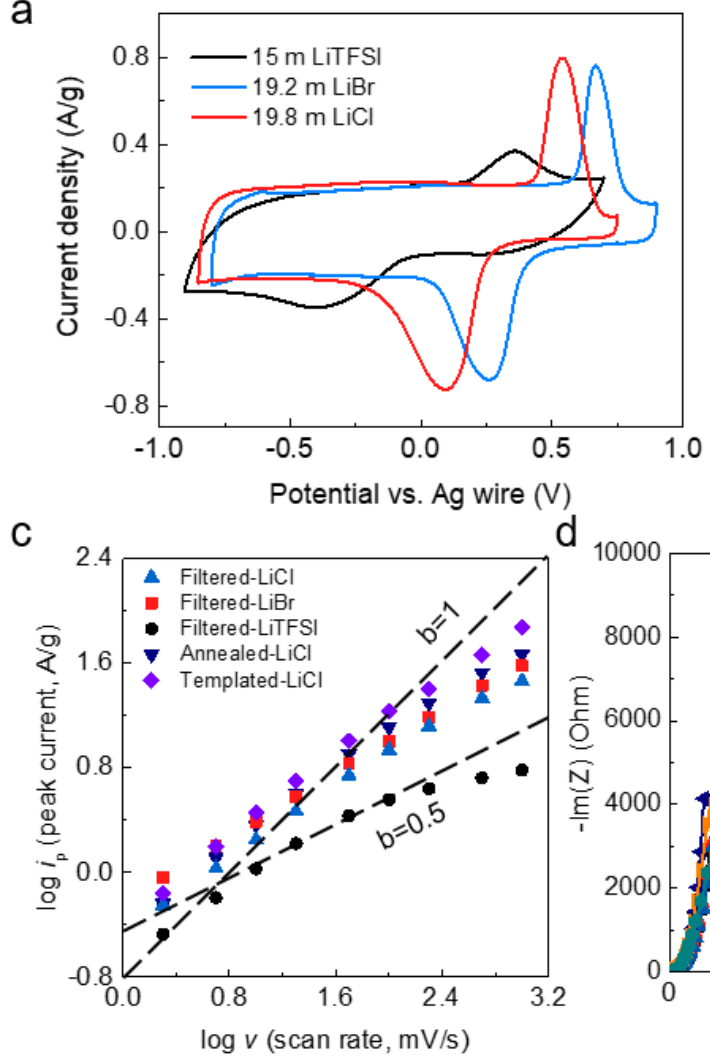

C

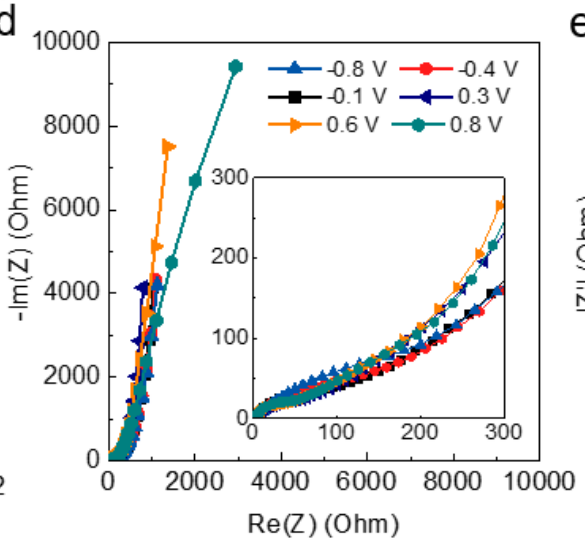

b

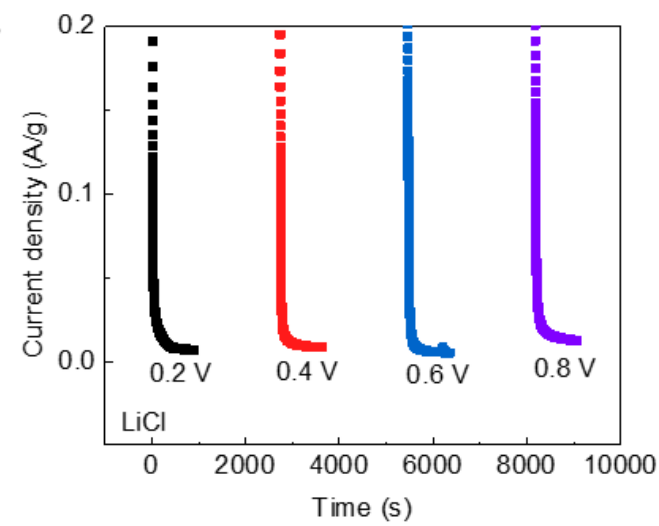

e

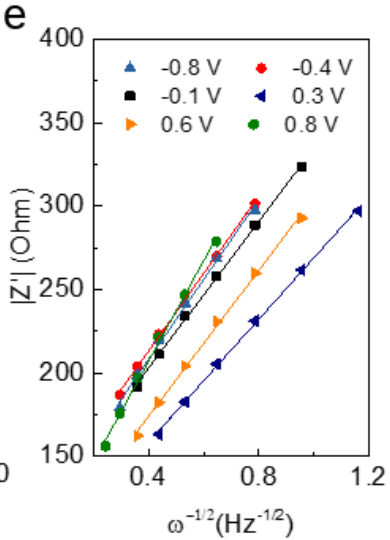

Figure 1. Electrochemical characterization of $\mathbf{T i}_{3} \mathbf{C}_{2} \mathbf{T}_{x}$ in WIS electrolytes. (a) Cyclic voltammograms for vacuum filtered $\mathrm{Ti}_{3} \mathrm{C}_{2} \mathrm{~T}_{x}$ electrodes collected at $2 \mathrm{mV} / \mathrm{s}$ in $19.8 \mathrm{~m} \mathrm{LiCl}, 19.2$ $\mathrm{m} \mathrm{LiBr}$ and $15 \mathrm{~m}$ LiTFSI. (b) Chronoamperometry data collected at different potentials in $19.8 \mathrm{~m}$ LiCl. The reference electrode is $\mathrm{Ag}$ and its potential vs $\mathrm{Ag} / \mathrm{AgCl}$ is given in Table $\mathrm{S} 1$. (c) Determination of the slope ( $b$ value) for the logarithm of the anodic peak current $\left(i_{\mathrm{p}}\right)$ versus the logarithm of the scan rate $(v)$ from 2 to $1,000 \mathrm{mV} / \mathrm{s}$. A $b$ value equal to 1 indicates non-diffusionlimited capacitive storage and $b$ value equal to 0.5 is characteristic of a diffusion-limited process. (d) Impedance spectra collected at different potentials for an annealed $\mathrm{Ti}_{3} \mathrm{C}_{2} \mathrm{~T}_{x}$ film in $19.8 \mathrm{~m} \mathrm{LiCl}$. The inset shows a magnified view of the impedance spectra in the high-frequency range. (e) Linear fit showing the relationship between the real impedance $(Z)$ and $\omega^{-1 / 2}$ in the Warburg frequency region. 
Extending the stable electrochemical potential window towards more positive potentials activates a new electrochemical process, as shown by the pair of strong peaks in the anodic and cathodic scans of the CV curves for $\mathrm{Ti}_{3} \mathrm{C}_{2} \mathrm{~T}_{x}$ in all three WIS electrolytes (Figure 1a and Figure S1). The two peaks in the WIS electrolytes correspond to a reversible process which contributes to increased charge storage capability (Figure S5). In contrast to the well-studied pseudocapacitive process for $\mathrm{Ti}_{3} \mathrm{C}_{2} \mathrm{~T}_{x}$ in $3 \mathrm{M} \mathrm{H}_{2} \mathrm{SO}_{4}$, there are large separations in potential $\left(\Delta E_{\mathrm{p}}\right)$ between the anodic and cathodic peaks in the WIS electrolytes. At a scan rate of $2 \mathrm{mV} / \mathrm{s}, \Delta E_{\mathrm{p}}$ values of $0.44 \mathrm{~V}, 0.41$ $\mathrm{V}$ and $0.76 \mathrm{~V}$ were recorded for the $\mathrm{LiCl}, \mathrm{LiBr}$ and LiTFSI WIS electrolytes, respectively. As the $\Delta E_{\mathrm{p}}$ in the $19.8 \mathrm{~m} \mathrm{LiCl}$ increases by only $0.07 \mathrm{~V}$ when the scan rate is increased $10 \mathrm{fold}$, the large $\Delta E_{\mathrm{p}}$ value is characteristic of what would be expected for a battery-type electrochemical process with slow reaction kinetics. ${ }^{3}$ The $b$ values (or the slopes of the log peak anodic currents $i_{\mathrm{p}} \sim \log$ scan rates $v$ curves) of each of the three WIS electrolytes were determined to be between 0.5 and 1.0 (Figure 1c), indicating that the electrochemical processes involves both surface and diffusioncontrolled kinetics ${ }^{3}$. Among the three WIS electrolytes, the electrochemical process in $15 \mathrm{~m}$ LiTFSI is the most diffusion-limited with the smallest $b$ value and largest $\Delta E_{\mathrm{p}}$, which can be explained by the highest viscosity and lowest ionic conductivity of $15 \mathrm{~m}$ LiTFSI (Table S1).

Nyquist plots recorded in the $19.8 \mathrm{~m} \mathrm{LiCl}$ electrolyte at different applied potentials show close to a vertical slope in the low-frequency region, except for a slight deviation at $0.8 \mathrm{~V}$ (Figure 1d). The vertical slope indicates either a close to ideal capacitive electrochemical process or a surfacereaction-controlled Faradaic process. ${ }^{16}$ Such behavior is also observed in battery materials with nanoscale particle sizes or extremely thin electrodes due to the ultra-short diffusion lengths. ${ }^{17}$ This is unlikely to be the case for the $\mathrm{Ti}_{3} \mathrm{C}_{2} \mathrm{~T}_{x}$ WIS systems, since the average flake size of the $\mathrm{Ti}_{3} \mathrm{C}_{2} \mathrm{~T}_{x}$ is $1.3 \mu \mathrm{m}$ and the electrode thickness is $>2 \mu \mathrm{m}$. Furthermore, the Warburg factor, or the slope of 
the linear fit of $Z_{\text {real }}$ versus $\omega^{-1 / 2}$ within the frequency range of the Warburg region, remains constant from -0.8 to $0.6 \mathrm{~V}$ (Figure 1e). This indicates that there are no changes in the ion diffusivity, even at the peak potentials. ${ }^{18}$ Interestingly, the surface-controlled capacitive behavior recorded in the electrochemical impedance spectra (EIS) and the unchanging ion diffusivity, even at the peak potentials, seem to directly contradict what would appear to be diffusion-controlled battery-like behavior based on the large $\Delta E_{\mathrm{p}}$ recorded in the voltammograms of the WIS electrolytes.

\section{Anomalous charging behavior}

In situ XRD analysis was performed to monitor changes in the interlayer spacing of the $\mathrm{Ti}_{3} \mathrm{C}_{2} \mathrm{~T}_{x}$ electrode during electrochemical cycling in the WIS electrolytes. The (002) peak, which corresponds to the $d$-spacing of $\mathrm{Ti}_{3} \mathrm{C}_{2} \mathrm{~T}_{x}$, was monitored for two cycles in the $19.8 \mathrm{~m} \mathrm{LiCl}$ electrolyte without pre-cycling (Figure 2a and Figure S6). The interlayer spacing changes were nearly identical for both cycles, indicating the reversibility of the process. The $d$-spacing of $\mathrm{Ti}_{3} \mathrm{C}_{2} \mathrm{~T}_{x}$ at the $\mathrm{OCP}(0.2 \mathrm{~V} v s \mathrm{Ag}$ for $19.8 \mathrm{~m} \mathrm{LiCl})$ increased slightly from $12.7 \AA$ to $12.9 \AA$ when negative potential was applied. The $d$-spacing did not change when scanning from the OCP to -0.8 $\mathrm{V}$ and then back to $0.3 \mathrm{~V}$, but an abrupt decrease from $12.9 \AA$ to $11.0 \AA$ was observed at $0.4 \mathrm{~V}$. The narrow interlayer spacing did not change from 0.4 to $0.8 \mathrm{~V}$, however when the electrode was cycled back to $0.24 \mathrm{~V}$, the interlayer spacing abruptly jumped from $11.0 \AA$ to $12.9 \AA$ over only a $100 \mathrm{mV}$ change in potential. The abrupt shrinkage and expansion of the $d$-spacing both occur at the onset potentials of the anodic (marked by black dots in Fig. 2a \& b) and cathodic (marked by red dots in Fig. 2a \& b) peaks in the CVs, respectively. Notably, the $d$-spacing changes continuously with the CV scan, even at the onset potentials, indicating there is no phase change during the process. 
a
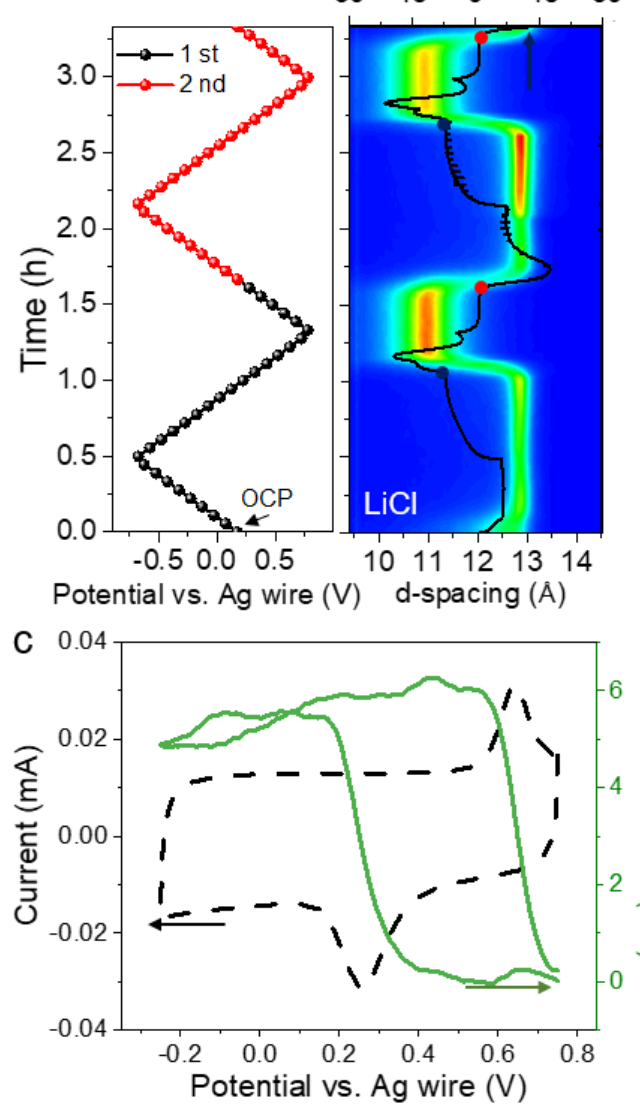

b

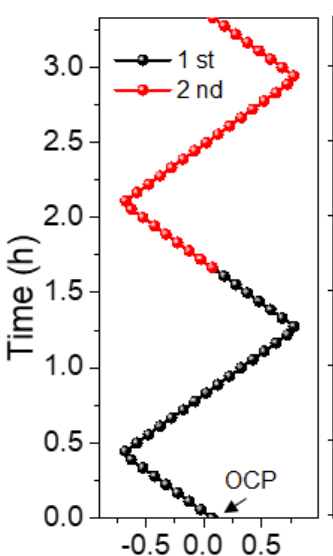

Potential vs. Ag wire (V)

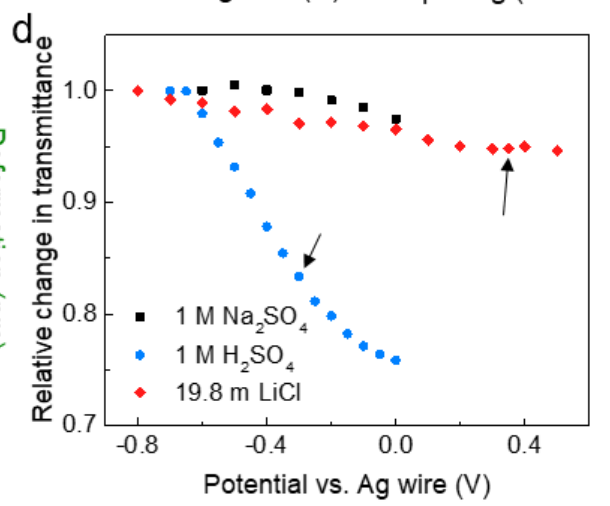

Current density $(\mu \mathrm{A})$

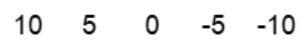

$\begin{array}{lllll}10 & 5 & 0 & -5 & -10\end{array}$

LiTFSI

$\begin{array}{lllll}10 & 11 & 12 & 13 & 14\end{array}$

d-spacing $(A)$

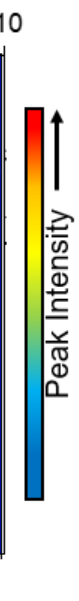

Figure 2. The evolution of the interlayer spacing of $\mathrm{Ti}_{3} \mathrm{C}_{2} \mathrm{~T}_{x}$ during cyclic voltammetry in

WIS electrolytes. d-spacing changes during cycling in (a) $19.8 \mathrm{~m} \mathrm{LiCl}$ electrolyte and (b) $15 \mathrm{~m}$ LiTFSI measured at a scan rate of $0.5 \mathrm{mV} / \mathrm{s}$ measured by in situ XRD. The intensities of the (002) diffraction peaks increases from blue to red, as shown in the scale bar. The black and red dots correspond to the onset potentials of the anodic (black) and cathodic (red) peaks in the CVs in Figure S6. (c) Changes in the deformation of the $\mathrm{Ti}_{3} \mathrm{C}_{2} \mathrm{~T}_{x}$ electrode during cycling at $100 \mathrm{mV} / \mathrm{s}$ in $19.8 \mathrm{~m} \mathrm{LiCl}$ monitored by operando atomic force microscopy (AFM). (d) Relative change in ultraviolet visible (UV-vis) transmittance ( $=\mathrm{UV}$ transmittance of specific potential/UV transmittance of $\mathrm{t}$ ) of the $\mathrm{Ti}_{3} \mathrm{C}_{2} \mathrm{~T}_{x}$ film as a function of applied potential vs Ag wire. Arrow marks the potential with peak in $\mathrm{CV}$. 
Operando atomic force microscopy (AFM) was used to further track the evolution of the local electrode deformation, $\delta$ (where $\delta>0$ was defined as electrode expansion and $\delta=0$ was set at the maximum potential), during electrochemical cycling. The AFM results agree with the behavior observed using in situ XRD, where the $\mathrm{Ti}_{3} \mathrm{C}_{2} \mathrm{~T}_{x}$ electrode experiences rapid expansion when scanned across the cathodic peak and then rapid contraction when scanned across the anodic peak in the $19.8 \mathrm{~m} \mathrm{LiCl}$ (Figure 2c). Mechanical cyclic voltammograms (mCVs), which are defined as the time differential of the electrode deformation $(d \delta / d t)$, resemble the electrochemical CVs (Figure S8), implying a linear $\delta$-charge $(Q)$ relationship at the potentials of the anodic and cathodic peaks. This relationship suggests that the electrochemical processes occurring at the peak potentials are different from what is occurring at potentials in the voltammograms where no peaks are present. ${ }^{19}$

As the onset potentials of the electrochemical processes occurring at the anodic and cathodic peaks are positive relative to the OCP in the WIS electrolytes, our first assumption was that the pair of peaks in the CVs were related to anion intercalation. However, the dramatic shrinkage of the interlayer space at the anodic peak and the expansion of the interlayer space at the cathodic peak indicates that anion intercalation and deintercalation does not play a role in the observed electrochemical process. Furthermore, approximately the same trend and magnitude of change in $d$-spacing were observed in the $15 \mathrm{~m}$ LiTFSI with larger anions size $\left(0.39 \times 0.8 \mathrm{~nm}^{\text {for TFSI }}{ }^{-}\right.$ versus $0.36 \times 0.36 \mathrm{~nm}$ for $\mathrm{Cl}^{-}$), which further rules out the possibility of anion intercalation (Figure 2b). Moreover, the $d$-spacing of $11 \AA$ (an interlayer spacing of $<3.1 \AA$ ) at the maximum positive potential is too small to accommodate either $\mathrm{Cl}^{-}$or TFSI- The small interlayer space at $0.8 \mathrm{~V} v s$ Ag also helps explain the lowest ion diffusivity and largest Warburg factor that was calculated from the EIS measurements at this potential (Figure 1e). Additionally, the potentials required for 
the reversible oxidation/reduction of an anion pair does not correlate well with the potentials of the electrochemical process in the $\mathrm{Ti}_{3} \mathrm{C}_{2} \mathrm{~T}_{x} /$ WIS system. Even the maximum applied potential of $0.8 \mathrm{~V} v s \mathrm{Ag}$ is not sufficient to oxidize any of the anions of the WIS electrolytes (Figure S7). Since anions are not involved in the process, the peaks observed at positive potentials should then be due to cation $\left(\mathrm{Li}^{+}\right)$insertion and de-insertion.

The position and intensity of the plasmon resonance peak of $\mathrm{Ti}_{3} \mathrm{C}_{2} \mathrm{~T}_{x}$ is known to shift during changes in the oxidation state of $\mathrm{Ti}$ caused by the transfer of charge from $\mathrm{Li}^{+}$to the $=\mathrm{O}$ terminations of MXene. ${ }^{20}$ A slow, constant decrease of the ultraviolet-visible (UV-vis) transmittance with increased potential was observed for the rectangular-shaped $\mathrm{CV}$ of $\mathrm{Ti}_{3} \mathrm{C}_{2} \mathrm{~T}_{x}$ in $1 \mathrm{M} \mathrm{Na}_{2} \mathrm{SO}_{4}$ (Figure $2 d$ and Figure S9), which indicates a contribution of pseudocapacitance with a small change in the Ti oxidation state. Ti oxidation state change was also observed by X-ray adsorption for $\mathrm{Ti}_{2} \mathrm{CT}_{x}$ MXene that had rectangular CVs. ${ }^{21}$ At the peak potentials in the voltammograms recorded in $\mathrm{H}_{2} \mathrm{SO}_{4}$, the rate of transmittance change increases, suggesting that the rate of charge transfer increases at the redox peak potentials in $\mathrm{H}_{2} \mathrm{SO}_{4}$. Conversely, despite there being intense, separated peaks in the CVs of the $19.8 \mathrm{~m} \mathrm{LiCl}$ electrolyte, the UV-vis transmittance decreases at a slow and almost constant rate with increasing potential, even at the $\mathrm{CV}$ peak potential. This indicates that the Faradaic process accompanying the peaks in $\mathrm{CV}$ in $19.8 \mathrm{~m} \mathrm{LiCl}$ is much weaker than that of the surface redox in $\mathrm{H}_{2} \mathrm{SO}_{4}$. Furthermore, the $\mathrm{Ti}_{2 \mathrm{p}}$ spectra are nearly identical for $\mathrm{Ti}_{3} \mathrm{C}_{2} \mathrm{~T}_{x}$ electrodes that were disassembled at $0.7 \mathrm{~V}$ and the $\mathrm{OCP}$, indicating that the Ti oxidation state change expected from a strong redox reaction is also missing (Figure S10).

All the experimental evidence suggests that the separated cathodic and anodic peaks in CVs observed for $\mathrm{Ti}_{3} \mathrm{C}_{2} \mathrm{~T}_{x}$ in the WIS electrolytes are not due to diffusion-limited Faradic processes. Instead, the surface-controlled behavior observed using EIS (Figure 1d) dominates the observed 
electrochemical response. Furthermore, the charge storage mechanism in the WIS electrolytes at positive potentials is different from the type of pseudocapacitive charge storage that is typically associated with MXenes in protic electrolytes where surface redox dominates and minor changes in lattice spacing occur during intercalation. ${ }^{22}$ The voltammetry of the Li-based WIS electrolytes is also distinctly different from the pseudocapacitive $\mathrm{Li}^{+}$intercalation peaks that was observed below $-0.5 \mathrm{~V} v s \mathrm{Ag}$ in organic LiTFSI electrolytes. ${ }^{9}$ In all three WIS electrolytes, however, the onset potential for anodic peak is more positive than both the potential of classical proton pseudocapacitive intercalation ${ }^{23,24}$ and even the OCP of $\mathrm{Ti}_{3} \mathrm{C}_{2} \mathrm{~T}_{x}$ in the WIS electrolytes. Hence, the $\mathrm{Li}^{+}$insertion/desertion observed in the WIS electrolytes at positive potentials is a distinct electrochemical process, which is unlike any previously reported system.

\section{Desolvation-free cation insertion}

To further investigate the charging mechanism of the WIS electrolytes, the relationship between the mass change caused by the insertion/desertion of electrolytes species and the abrupt interlayer spacing changes of the $\mathrm{Ti}_{3} \mathrm{C}_{2} \mathrm{~T}_{x}$ electrode was measured using an electrochemical quartz crystal microbalance with dissipation monitoring (EQCM-D) in $19.8 \mathrm{~m} \mathrm{LiCl}$ (Figure 3a \& b). The added mass of the electrode was correlated with changes in the resonance frequency $(\Delta f / n)$ following the Sauerbrey equation. Three electrochemical stages (S1-S3) were identified during the cathodic scan: (S1) From $0.45 \mathrm{~V}$ to $0.17 \mathrm{~V}$, where almost no water accompanied the inserted $\mathrm{Li}^{+}$. (S2) As soon as the potential reaches $0.17 \mathrm{~V}$ (red dot, onset potential of the cathodic peak), a dramatic increase in the amount of inserted water was observed, corresponding to 2.85 water molecules per intercalated $\mathrm{Li}^{+}$. This water $/ \mathrm{Li}^{+}$ratio is similar to the hydration number for $\mathrm{Li}^{+}$in the bulk WIS electrolyte $\left(\sim 2.80\right.$, Table S1), meaning that desolvation did not occur for the $\mathrm{Li}^{+}$ insertion process at the peak potentials in the WIS electrolytes, which is different from previous 
observations showing that the desolvation of $\mathrm{Li}^{+}$occurs upon intercalation into $\mathrm{Ti}_{3} \mathrm{C}_{2} \mathrm{~T}_{x} \cdot{ }^{13}$ Previous computational results suggest that desolvation-free $\mathrm{Li}^{+}$intercalation should result in EDL formation in MXenes in order to the maintain charge separation ${ }^{25}$, which is in agreement with the weak partial charge transfer observed by UV-vis. (S3) When the peak starts to fade below $0.05 \mathrm{~V}$ (yellow dot), the number of water molecules entering the $\mathrm{Ti}_{3} \mathrm{C}_{2} \mathrm{~T}_{x}$ with the $\mathrm{Li}^{+}$drops to 1.45 water per Li ion, which is similar to the value observed in Li-based salt-in-water electrolytes. ${ }^{26}$ Reversibly, a greater number of water molecules per $\mathrm{Li}^{+}$leaves the interlayer space of the $\mathrm{Ti}_{3} \mathrm{C}_{2} \mathrm{~T}_{x}$ at the onset potential of the anodic peak (from the black dot to the blue dot in Figure 3a) versus the peak-free region when the system cycles back from negative to positive potentials.

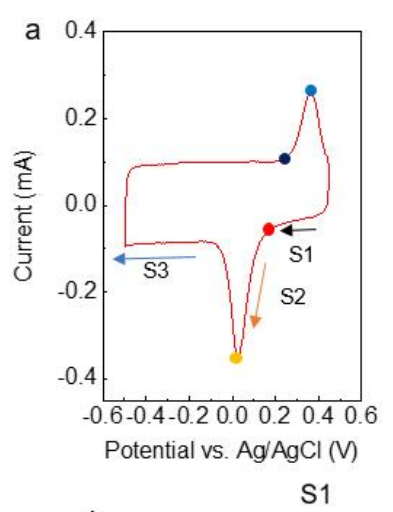

d

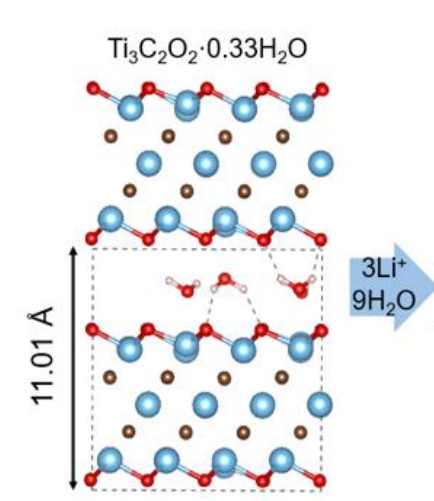

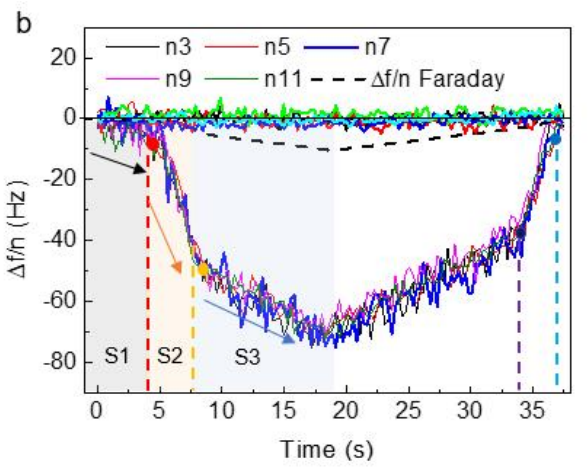

S2

$\mathrm{Ti}_{3} \mathrm{C}_{2} \mathrm{O}_{2} \cdot 1.08 \mathrm{H}_{2} \mathrm{O} \cdot 0.25 \mathrm{Li}$

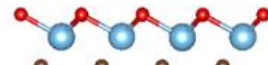

- $\circ$.
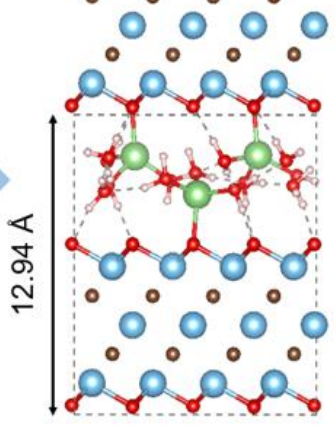

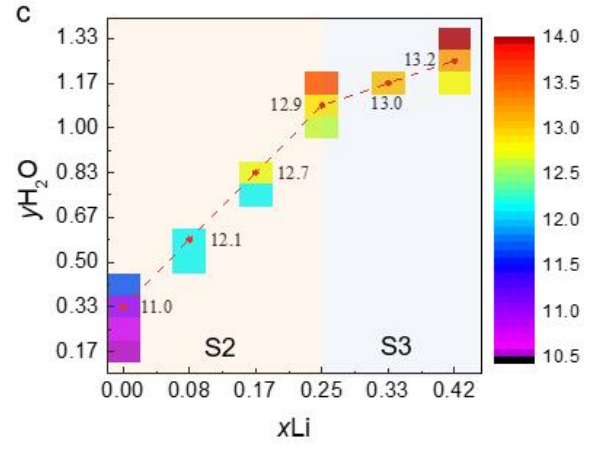

S3

$\mathrm{Ti}_{3} \mathrm{C}_{2} \mathrm{O}_{2} \cdot 1.25 \mathrm{H}_{2} \mathrm{O} \cdot 0.42 \mathrm{Li}$

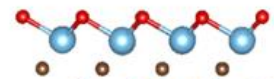

- 0 ○ 0
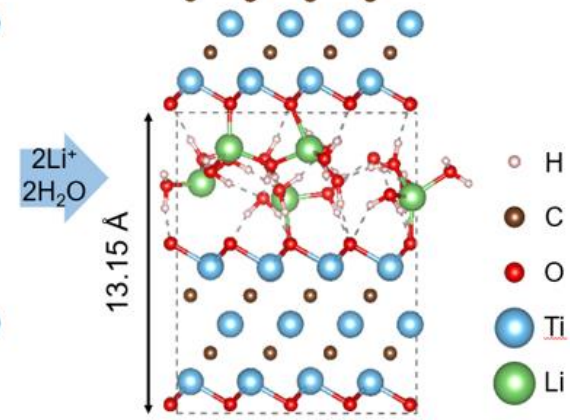

Figure 3. Changes in the populations of intercalated species during cycling of $\mathrm{Ti}_{3} \mathrm{C}_{2} \mathrm{~T}_{x}$ in 19.8

m LiCl. (a) Cyclic voltammogram recorded during electrochemical quartz crystal microbalance 
(EQCM) measurements. (b) Time-dependent changes of the resonance frequency $\Delta f / n$ during the insertion/extraction of $\mathrm{Li}^{+}$and water. (c) The $d$-spacings for various $\mathrm{Ti}_{3} \mathrm{C}_{2} \mathrm{O}_{2} \cdot x \mathrm{Li} \cdot y \mathrm{H}_{2} \mathrm{O}$ as optimized by density functional theory (DFT) simulations. (d) Structure of $\mathrm{Ti}_{3} \mathrm{C}_{2} \mathrm{O}_{2}$ with different interlayer compositions: $\quad \mathrm{Ti}_{3} \mathrm{C}_{2} \mathrm{O}_{2} \cdot 0.33 \mathrm{H}_{2} \mathrm{O}, \quad \mathrm{Ti}_{3} \mathrm{C}_{2} \mathrm{O}_{2} \cdot 1.08 \mathrm{H}_{2} \mathrm{O} \cdot 0.25 \mathrm{Li}$ and $\mathrm{Ti}_{3} \mathrm{C}_{2} \mathrm{O}_{2} \cdot 1.25 \mathrm{H}_{2} \mathrm{O} \cdot 0.42 \mathrm{Li}$ from left to right.

Density functional theory (DFT) simulations (Figure 3c and 3d) were performed to quantitatively correlate the changes in $d$-spacing with the intercalated species. We found that the $\mathrm{S} 1$ state is best represented by a composition of $\mathrm{Ti}_{3} \mathrm{C}_{2} \mathrm{O}_{2} \cdot 0.33 \mathrm{H}_{2} \mathrm{O}$, whose $11.01 \AA d$-spacing from DFT closely matches the experimental $d$-spacing. We then inserted different numbers of water molecules and $\mathrm{Li}^{+}$ions and optimized the $d$-spacings of various $\mathrm{Ti}_{3} \mathrm{C}_{2} \mathrm{O}_{2} \cdot x \mathrm{Li} \cdot y \mathrm{H}_{2} \mathrm{O}$ compositions (Figure 3c and Figure S11). The changes in the $d$-spacing for the $\mathrm{S} 2$ stage is best matched by cointercalation of a 3:1 ratio of $\mathrm{H}_{2} \mathrm{O}$ and $\mathrm{Li}^{+}$(close to the experimental value of 2.85 from EQCM), reaching a $d$-spacing of $12.94 \AA$ for the composition $\mathrm{Ti}_{3} \mathrm{C}_{2} \mathrm{O}_{2} \cdot 0.25 \mathrm{Li} \cdot 1.08 \mathrm{H}_{2} \mathrm{O}$, which matches well the XRD-measured $d$-spacing changes occurring during the cathodic scan (from $11.0 \AA$ to 12.9 $\AA$ ). $\mathrm{As} \mathrm{Li}^{+}$ions are further inserted into the interlayer space (S3), we found that a significantly reduced $\mathrm{H}_{2} \mathrm{O} / \mathrm{Li}^{+}$ratio (1:1) best captures the almost constant $d$-spacing of $\sim 13.0 \AA$ in this regime. Hence, the (de)intercalation of the solvated $\left[\mathrm{Li}\left(\mathrm{H}_{2} \mathrm{O}\right)_{3}\right]^{+}$species accounts for the large variations in the $d$-spacing and is responsible for the peaks seen in the CVs in the WIS electrolytes. Further DFT simulations of the intercalation energy and voltage confirm that the S2 stage has a higher thermodynamic driving force than the $\mathrm{S} 3$ stage for the intercalation of $\mathrm{Li}^{+}$ions (Figure $\mathrm{S} 12 \mathrm{a}$ ) and that the $\mathrm{S} 2$ stage has a much wider plateau at $0.5 \mathrm{~V} v s \mathrm{Ag} / \mathrm{AgCl}$ in the intercalation voltage $v s x \mathrm{Li}$ plot (Figure S12b), agreeing well with the midpoint between the cathodic and anodic peaks in 
Figure 1a. As described in the previous sections, the stage S2 is not correlated with a distinct diffusion-controlled charge transfer process and is different from the typical pseudocapacitive processes. We define this surface-controlled, desolvation-free $\mathrm{Li}^{+}$insertion process as the mechanically coupled formation/removal of a confined pseudocapacitive intercalation between conducting 2D sheets.

\section{Significance of the desolvation-free process}

Despite the high viscosity of the WIS electrolytes, this potential-driven abrupt loss/gain of $\mathrm{Li}^{+}$is a high-rate process, likely because it is mainly surface-controlled, desolvation-free, and not accompanied by intercalation of large anions (Figure 4a). By using $\mathrm{Ti}_{3} \mathrm{C}_{2} \mathrm{~T}_{x}$ electrodes with a wavy layer morphology ${ }^{27}$ (denoted as templated MXene, Figure S13), the ion diffusion resistance can be significantly reduced in the WIS electrolyte (Figure S14), with electrochemical kinetics that are less diffusion-controlled and have a larger $b$ value than the filtered $\mathrm{Ti}_{3} \mathrm{C}_{2} \mathrm{~T}_{x}$ film electrode (Figure 1c). A pair of strong, separated peaks can still be observed in the CVs of the templated $\mathrm{Ti}_{3} \mathrm{C}_{2} \mathrm{~T}_{x}$ electrode (Figure $4 \mathrm{~b}$ ), which matches well with the two noticeable plateaus in the galvanostatic charge-discharge curves (Figure 4c). The templated $\mathrm{Ti}_{3} \mathrm{C}_{2} \mathrm{~T}_{x}$ had a high capacitance retention of $68 \%$ at a scan rate of $1,000 \mathrm{mV} / \mathrm{s}$ in the $19.2 \mathrm{~m} \mathrm{LiBr}$, and still stored/delivered a capacitance of 28 $\mathrm{F} / \mathrm{g}\left(59 \mathrm{~F} / \mathrm{cm}^{3}\right)$ at a scan rate of up to $10,000 \mathrm{mV} / \mathrm{s}$ (Figure $4 \mathrm{~d}$ ).

Due to the improved oxidation resistance of $\mathrm{Ti}_{3} \mathrm{C}_{2} \mathrm{~T}_{x}$ in the WIS electrolytes, a large voltage window of $1.6 \mathrm{~V}$ is possible for $\mathrm{Ti}_{3} \mathrm{C}_{2} \mathrm{~T}_{x}-\mathrm{Ti}_{3} \mathrm{C}_{2} \mathrm{~T}_{x}$ two-electrode cells using the $19.8 \mathrm{~m} \mathrm{LiCl}$ electrolyte (Figure 4e), which is 2.7 times larger than comparable two-electrode cells in acidic electrolytes ${ }^{28}$. A pair of separated peaks was observed in the individual voltammograms of the positive and negative $\mathrm{Ti}_{3} \mathrm{C}_{2} \mathrm{~T}_{x}$ electrodes (Figure $\mathrm{S} 15 \mathrm{a}$ ), indicating that the desolvation-free $\mathrm{Li}^{+}$ 
insertion contributes to the performance of the full device. The templated $\mathrm{Ti}_{3} \mathrm{C}_{2} \mathrm{~T}_{x}-\mathrm{Ti}_{3} \mathrm{C}_{2} \mathrm{~T}_{x}$ twoelectrode cell had a capacitance of $26 \mathrm{~F} / \mathrm{g}$ or $55 \mathrm{~F} / \mathrm{cm}^{3}$ (based on the mass of both electrodes, corresponding to an average of $104 \mathrm{~F} / \mathrm{g}$ or $220 \mathrm{~F} / \mathrm{cm}^{3}$ per electrode) in $19.8 \mathrm{~m} \mathrm{LiCl}$ at $2 \mathrm{mV} / \mathrm{s}$ (Figure S15b).

The de-solvation free process can be combined with other types of electrochemical processes to further enhance the charge storage capability of $\mathrm{Ti}_{3} \mathrm{C}_{2} \mathrm{~T}_{x}$. In the $19.2 \mathrm{~m} \mathrm{LiBr}$ electrolyte, the electrode can be charged to $1.15 \mathrm{~V}$ with a Coulombic efficiency $>95 \%$. Besides the peaks discussed earlier, another pair of peaks with a close-to-zero $\Delta E_{\mathrm{p}}$ appear when the cell is charged beyond $1 \mathrm{~V}$ vs $\mathrm{Ag}$ (Figure 4f and Figure S16) due to the oxidation/reduction of $\mathrm{Br}^{-}$at the $\mathrm{Ti}_{3} \mathrm{C}_{2} \mathrm{~T}_{x}$ electrode, as confirmed by similar observations for activated carbon (Figure S16c). Developing MXene compositions with higher oxidation stability ${ }^{29}$ should in turn allow the utilization of other types of reversible electrochemical processes, such as the intercalation and redox of anions in confinement between the layers of MXenes.

Due to its metallic conductivity and excellent mechanical properties, $\mathrm{Ti}_{3} \mathrm{C}_{2} \mathrm{~T}_{x}$ does not require the use of metallic current collectors during device fabrication, enabling the usage of cheap but corrosive halide WIS electrolytes. This is a change that could significantly reduce the price of supercapacitor systems where a major portion of device cost lies in the electrolyte and the metal foils that are used as current collectors. ${ }^{30}$ Desolvation-free cation insertion was also observed in 6 $\mathrm{m} \mathrm{NaCl}$, though the performance degraded within several cycles (Figure S17). The lower concentration of the saturated $\mathrm{NaCl}$ electrolyte may result in quick degradation of $\mathrm{Ti}_{3} \mathrm{C}_{2} \mathrm{~T}_{x}$, similar to what occurs in $\mathrm{LiCl}$ electrolytes at lower concentrations (Figure S1). Another crucial factor to realize and/or stabilize the peaks at positive potentials in WIS electrolytes is to use high-quality $\mathrm{Ti}_{3} \mathrm{C}_{2} \mathrm{~T}_{x}$ with improved stoichiometry and stability (as described in ref. ${ }^{31}$ ). We assume that oxide 
nanoparticles formed at the edges and defects of defective $\mathrm{Ti}_{3} \mathrm{C}_{2} \mathrm{~T}_{x}$ flakes may hinder the reversible shrinkage of the interlayer space and prevent electrolyte removal. The CVs of lower quality $\mathrm{Ti}_{3} \mathrm{C}_{2} \mathrm{~T}_{x}$ do not show obvious peaks, or in some cases no peaks can be seen, in $19.8 \mathrm{~m} \mathrm{LiCl}$ (Figure S18). This observation also shows that dimensional changes of the electrodes can be eliminated by pillaring the MXenes sheets when large dimensional changes are not desired. At the same time, the significant changes in dimension over such a narrow range of potentials under $1 \mathrm{~V}$ can be effectively used in developing MXene-based actuators ${ }^{32}$. Other 2D materials with variable interlayer spacing or stretchable 3D porous networks may also show similar electrochemical behavior through the use of solvent-in-salt electrolytes. Further revealing its relationship with the electrical conductivity and dielectric properties will benefit the development of other applications, including electromagnetic energy conversion and electromagnetic interference shielding. ${ }^{33-35}$
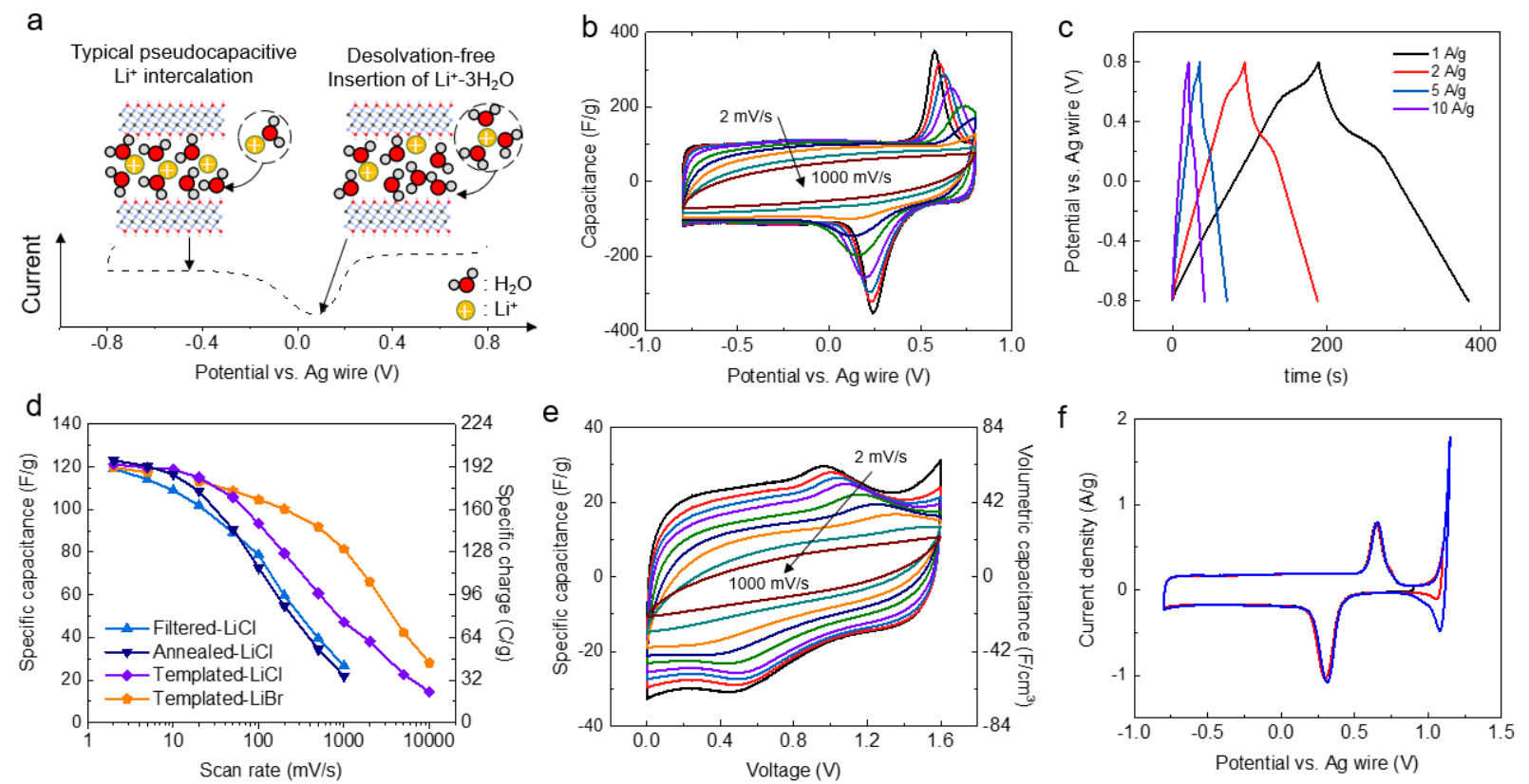

Figure 4. Electrochemical performance of $\mathrm{Ti}_{3} \mathrm{C}_{2} \mathrm{~T}_{x}$ in WIS electrolytes. (a) Schematic illustrating the difference between typical pseudocapacitive intercalation and the desolvation-free 
intercalation observed in $\mathrm{Ti}_{3} \mathrm{C}_{2} \mathrm{~T}_{x}$ in WIS electrolytes. (b) Three-electrode cyclic voltammograms curves of wavy $\mathrm{Ti}_{3} \mathrm{C}_{2} \mathrm{~T}_{x}$ in $19.8 \mathrm{~m} \mathrm{LiCl}$, the scan rates from the outer cycle to the inner cycle are 2, 5, 10, 20, 50, 100, 200, 500 and $1000 \mathrm{mV} / \mathrm{s}$. (c) Three-electrode galvanostatic charge-discharge curves of the wavy $\mathrm{Ti}_{3} \mathrm{C}_{2} \mathrm{~T}_{x}$ in $19.8 \mathrm{~m} \mathrm{LiCl}$ at current densities of $1,2,5$ and $10 \mathrm{~A} / \mathrm{g}$. (d) Capacitance retention of different $\mathrm{Ti}_{3} \mathrm{C}_{2} \mathrm{~T}_{x}$ electrodes in $19.8 \mathrm{~m} \mathrm{LiCl}$ and $19.2 \mathrm{~m} \mathrm{LiBr}$. (e) Cyclic voltammograms of a $\mathrm{Ti}_{3} \mathrm{C}_{2} \mathrm{~T}_{x}-\mathrm{Ti}_{3} \mathrm{C}_{2} \mathrm{~T}_{x}$ two-electrode cell in $19.8 \mathrm{~m} \mathrm{LiCl}$, the scan rates from the outer cycle to the inner cycle are 2, 5, 10, 20, 50, 100, 200, 500 and $1000 \mathrm{mV} / \mathrm{s}$. (f) Three-electrode cyclic voltammograms of the templated $\mathrm{Ti}_{3} \mathrm{C}_{2} \mathrm{~T}_{x}$ electrode in $19.2 \mathrm{~m} \mathrm{LiBr}$ when the upper limit of the potential goes beyond $0.8 \mathrm{~V}$.

\section{Conclusions}

In this study, a desolvation-free $\mathrm{Li}^{+}$insertion charging mechanism was observed for $\mathrm{Ti}_{3} \mathrm{C}_{2} \mathrm{~T}_{x}$ MXene in WIS electrolytes. The process shows electrochemical characteristics identical to batterylike (diffusion-controlled) materials but was found to instead be caused by a surface-controlled charge storage process, where partial charge transfer processes could be observed at the potentials corresponding to the peaks in the voltammograms. In addition, this process is distinct from typical capacitive or pseudocapacitive charge storage due to the abrupt reversible interlayer space changes occurring when solvated $\mathrm{Li}^{+}$enters and exits the interlayer spaces of $\mathrm{Ti}_{3} \mathrm{C}_{2} \mathrm{~T}_{x}$ that is accompanied by sharp peaks with large peak potential separation. By extending the ion insertion potential and improving the oxidation resistance of $\mathrm{Ti}_{3} \mathrm{C}_{2} \mathrm{~T}_{x}$, the desolvation-free ion insertion process opens up opportunities for development of a new generation of devices for high-rate, high-energy storage and harvesting, as well as potential applications in sensing and actuation. By further increasing the 
cell potential to facilitate the reversible redox of halogen ions in confinement, there is potential for further increasing the amount of energy stored by 2D materials with confined electrolytes.

\section{Methods}

\section{Materials}

Preparation of $\mathrm{Ti}_{3} \mathrm{AlC}_{2} \mathrm{MAX}$ with improved stoichiometry and crystallinity

The $\mathrm{Ti}_{3} \mathrm{AlC}_{2}$ MAX phase was prepared following the method described in detail in $\mathrm{ref}^{36}$. In brief, $\mathrm{TiC}, \mathrm{Ti}$, and $\mathrm{Al}$ powders with a mass ratio of 2:1:1 were mixed by ball milling at $70 \mathrm{rpm}$ for $18 \mathrm{~h}$ before heating in a tube furnace. Excess aluminum used was found to improve the MAX phase stoichiometry and crystallinity of $\mathrm{Ti}_{3} \mathrm{AlC}_{2}$ grains. During the reaction sintering, the precursor mixture powder was heated up to $1380{ }^{\circ} \mathrm{C}$ with a heating rate of $3{ }^{\circ} \mathrm{C} / \mathrm{min}$, held at the maximum temperature for $2 \mathrm{~h}$ and cooled at a rate of $3{ }^{\circ} \mathrm{C} / \mathrm{min}$. The MAX phase synthesis process was conducted under a constant Ar flow of $100 \mathrm{sccm}$. After synthesis, the sintered MAX phase block was milled into powder. The powder was washed with $9 \mathrm{M} \mathrm{HCl}$ until gas bubbles from the solution stops and neutralized by repeated washing with deionized water. Finally, the MAX phase powder was dried in vacuum oven at $80{ }^{\circ} \mathrm{C}$ overnight and sieved through a 450 -mesh sieve.

\section{$\mathrm{Ti}_{3} \mathrm{C}_{2}$ MXene prepared by $\mathrm{HF} / \mathrm{HCl}$ etching}

$1 \mathrm{~g}$ of $\mathrm{Ti}_{3} \mathrm{AlC}_{2} \mathrm{MAX}$ powder was etched in $20 \mathrm{~mL}$ of a mixture of $12 \mathrm{M} \mathrm{HCl}$, deionized water and $50 \mathrm{wt} \% \mathrm{HF}$ with a volume ratio of $6: 3: 1$ at a stirring speed of $400 \mathrm{rpm}$ for $24 \mathrm{~h}$ at $35^{\circ} \mathrm{C}$. The etched $\mathrm{Ti}_{3} \mathrm{C}_{2} \mathrm{~T}_{x}$ was washed by deionized water through centrifugation until the $\mathrm{pH}$ of supernatant reached $\sim 6$. Then, the etched $\mathrm{Ti}_{3} \mathrm{C}_{2}$ multilayer sediment was dispersed in a $0.5 \mathrm{M} \mathrm{LiCl}$ solution and stirred at $400 \mathrm{rpm}$ for $4 \mathrm{~h}$ at room temperature. Afterwards, the $\mathrm{Ti}_{3} \mathrm{C}_{2}$ was washed with 
deionized water through centrifugation for 5 times, and the supernatant containing well-dispersed MXene colloidal solution of single- and few-layer MXene flakes was collected.

\section{Preparation of vacuum filtered $\mathrm{Ti}_{3} \mathrm{C}_{2}$ thin film and annealed $\mathrm{Ti}_{3} \mathrm{C}_{2}$ film}

The vacuum filtered $\mathrm{Ti}_{3} \mathrm{C}_{2} \mathrm{~T}_{x}$ thin film (denoted as filtered MXene) was directly obtained by filtrating the well-dispersed MXene colloidal solution through a $25 \mu \mathrm{m}$-thick Celgard 3501 polypropylene membrane and peeling the film from the Celgard. The film with a density of 2.6 $\mathrm{g} / \mathrm{cm}^{3}$, was dried in the vacuum oven at $80{ }^{\circ} \mathrm{C}$ overnight. To remove the strongly adsorbed intercalated water, the vacuum filtered $\mathrm{Ti}_{3} \mathrm{C}_{2}$ film was annealed at $370{ }^{\circ} \mathrm{C}$ for $30 \mathrm{~min}$ (heat rate of $5{ }^{\circ} \mathrm{C} / \mathrm{min}$ ) under $100 \mathrm{sccm}$ Ar flow (sample denoted as annealed MXene).

\section{Preparation of the templated $\mathrm{Ti}_{3} \mathrm{C}_{2} T_{x}$ MXene film}

The polystyrene (PS) spheres were prepared by polymerizing styrene monomer, as reported by Park et al. ${ }^{37}$ First, $100 \mathrm{mg}$ polyvinyl pyrrolidone and $102.6 \mathrm{mg}$ ammonium persulfate were mixed with a solution containing $230 \mathrm{~mL}$ ethanol and $30 \mathrm{~mL}$ deionized water for $10 \mathrm{~min}$ at room temperature. Afterwards, $22 \mathrm{~mL}$ styrene monomer was added into the solution mixture by once with quick stirring at $70{ }^{\circ} \mathrm{C}$. The mixture was kept stirring for $24 \mathrm{~h}$ at $70{ }^{\circ} \mathrm{C}$, followed by cooling in the ice bath for $30 \mathrm{~min}$. The PS spheres were collected by centrifuging and washing with deionized water and ethanol afterwards. Then, the PS sphere dispersion in water was sonicated with MXene colloidal solution (the mass ratio between PS and $\operatorname{Ti}_{3} \mathrm{C}_{2} \mathrm{~T}_{x}$ was 2:1) for $10 \mathrm{~min}$. The mixed solution was vacuum filtered through the Celgard 3501 membrane, and the produced film was peeled off from the membrane and dried overnight at $80{ }^{\circ} \mathrm{C}$. After annealing the MXene-PS film at $450{ }^{\circ} \mathrm{C}$ for $1 \mathrm{~h}$ (heating rate $5{ }^{\circ} \mathrm{C} / \mathrm{min}$ ) under an Argon flow, the macroporous MXene was 
obtained. By further pressing the macroporous MXene on a smooth PET film, a MXene film with wavy structure (denoted as templated MXene) and a density of $2.1 \mathrm{~g} / \mathrm{cm}^{3}$ was obtained. ${ }^{23}$

\section{Testing and characterization}

Chemical composition of the samples was analyzed by X-ray photoelectron spectroscopy (XPS) with a Physical Electronics VersaProbe 5000 instrument (UK) equipped with a monochromatic Al-K $\mathrm{K}_{\alpha}$ X-ray source $(\mathrm{h} v=1486.6 \mathrm{eV})$. For the ex-situ XPS analysis, the MXene films were first precycled in the three-electrode Swagelok cells for 5 times. Two cycled MXene films were collected at the potential of $0 \mathrm{~V}$ and $0.7 \mathrm{~V} v s$ a $\mathrm{Ag}$ wire, respectively, with a plastic tweezer. Before the XPS tests, all samples were Argon sputtered for 2 min. Peak fitting was carried out using CasaXPS software, version 2.3.16 RP 1.6. Raman spectra were recorded with a Renishaw Raman InVia Confocal Microscope (UK) with the $488 \mathrm{~nm}$ laser, $1200 \mathrm{gr} / \mathrm{mm}$ grating, 50× lens was used with 5\% laser power. Ex-situ X-ray diffraction (XRD) patterns of the MXene thin films were collected on a Rigaku MiniFlex (40 kV and $15 \mathrm{~mA}$ ) diffractometer using $\mathrm{Cu} \mathrm{K}_{\alpha}$ radiation. $\mathrm{N}_{2}$ sorption $\left(-196{ }^{\circ} \mathrm{C}\right)$ isotherms of carbon materials were recorded on a Quadrosorb gas sorption instrument (Quantachrome, USA). The samples were degassed at $200{ }^{\circ} \mathrm{C}$ for $12 \mathrm{~h}$ under turbomolecular vacuum pumping prior to the $\mathrm{N}_{2}$ gas adsorption measurements. The pore size distribution of the carbon material was calculated by applying quench-solid density functional theory (QSDFT) algorithm.

In-situ ultraviolet-visible (UV-vis) spectrometry was conducted from 300 to $1000 \mathrm{~nm}$ on a Thermo Fisher Scientific Evolution 201. The cells used $\mathrm{Ti}_{3} \mathrm{C}_{2} \mathrm{~T}_{\mathrm{x}}$ MXene sprayed coated glass as both the working and counter electrode, and sliver wire as the reference electrode. The counter electrode was overcapacitive, and there was a window (about $1 \mathrm{~cm}$ in diameter) on the counter 
electrode that was not coated by MXene. The cell was precycled in each electrolyte for 5 times, and the UV-vis spectra were recorded from the negative to the positive potential with a step of $0.05 \mathrm{~V}$ or $0.1 \mathrm{~V}$ at $20 \mathrm{mV} / \mathrm{s}$. At each step, the potential was kept for 1 min before the UV-vis measurement.

Operando electrochemical atomic force microscopy (AFM) measurements were conducted in a three-electrode electrochemical AFM cell (Asylum Research, Oxford Instruments, USA) with a ring-shape glassy carbon counter electrode and a Pt or Ag quasi-reference electrode. The electrode was prepared by dropcasting MXene solution onto a glassy carbon substrate and dried under 60 ${ }^{\circ} \mathrm{C}$ overnight. The thickness of the deposited MXene film was between $30-60 \mathrm{~nm}$. Cyclic voltammetry measurements were performed using a Bio-Logic SP-200 potentiostat. The local MXene deformation during cycling was monitored with an MFP-3D AFM (Asylum Research, Oxford Instruments, USA) by performing force-distance measurements. The AFM tips used in this study were from BudgetSensor with a nominal spring constant of $3 \mathrm{~N} / \mathrm{m}$. Once the AFM tip was in contact with the MXene electrode and reached its setpoint, the cantilever held its position and sent a trigger to the potentiostat to perform the $\mathrm{CV}$ for 7 cycles. The electrode deformation during cycling was monitored via AFM deformation channel. The deformation data measured by AFM on one spot was first subjected to baseline subtraction to correct the thermal drift and smoothed with a moving average or Savitzky-Golay filter. The average of the 7 cycles was calculated and the deformation rate (time differentiate of the deformation) was calculated using the averaged deformation.

In situ XRD measurements were performed on a Bruker D8 Advance diffractometer using Cu $\mathrm{K}_{\alpha}$ radiation source. A lab-made three-electrodes cell, using a $\mathrm{Ti}_{3} \mathrm{C}_{2} \mathrm{~T}_{x}$ MXene film as the working electrode, an overcapacitive YP50F film as the counter electrode, and a Ag wire as the reference 
electrode, was used to perform the electrochemical cycling in the in situ XRD measurements. The cell setup is similar to a previous report, ${ }^{38}$ with a glassy carbon rod as the current collector. Two electrolytes were selected for the in situ XRD tests, namely $19.8 \mathrm{~m} \mathrm{LiCl}$ and $21 \mathrm{~m} \mathrm{LiTFSI}$. All XRD patterns were recorded during the cyclic voltammetry test, starting from the open circuit potential with a potential scan rate of $0.5 \mathrm{mV} \mathrm{s}^{-1}$. The (002) peaks of $\mathrm{Ti}_{3} \mathrm{C}_{2} \mathrm{~T}_{x}$ MXene located between $5^{\circ}$ to $10^{\circ} 2 \Theta$ were recorded to calculate the interlayer $d$-spacing.

Electrochemical Quartz Crystal Microbalance (EQCM) analyses was conducted using a QCM-D instrument (Bioline Scientific) connected to a potentiostat station (BioLogic SP-300, France) using Au coated quartz sensors (AWS). Prior to the measurements, the quartz crystals were cleaned by oxygen plasma for $5 \mathrm{~min}$. A thin film of MXene was deposited on the sensors from a aqueous suspension $\left(0.1 \mathrm{mg} \mathrm{Ti}_{3} \mathrm{C}_{2} / \mathrm{ml}\right)$ by nitrogen assisted airbrush to get a mass loading of $26.5 \mu \mathrm{g} / \mathrm{cm}^{2}$. The high rigidity of the coating was confirmed from the small frequency changes measured in air (less than 2 units of dissipation for all the measured overtones). The electrochemical measurements were performed in a three-electrodes configuration using $\mathrm{Ag} / \mathrm{AgCl}$ and $\mathrm{Grafoil}^{\mathrm{O}}$ as reference and counter electrode, respectively. To reduce the viscosity of the highly concentrated $\mathrm{LiCl}$ solution, the EQCM-D cell was heated to a $65{ }^{\circ} \mathrm{C}$. This temperature was kept constant all over the experiments. After stabilization of the recorded QCM signals, the electrochemical behavior of the coated MXene was measured by $\mathrm{CV}$ at $50 \mathrm{mV} / \mathrm{s}$. Typical response observed was defined by oxidation and reduction peaks at $0.37 \mathrm{~V}$ and $0.02 \mathrm{~V}$ respectively.

As previously reported ${ }^{39}$, accurate quantification of potential induced gravimetric changes requires the existence of two conditions: (1) small dissipation changes over the entire electrochemical process (2) Overtone independent reposts of the normalized frequency namely $F_{\mathrm{n}} / n=$ const. As long as both conditions are met, the response can be considered as purely 
gravimetric, i.e., the frequency is shifting only due to accumulation/removal of the mass and is not influenced by the viscoelasticity of the morphological state of the electrode. An overtone independent frequency shift followed by negligible dissipation changes was observed during a potential scan from the positive to the negative vertex and on the reverse way. The dashed black line represents the expected frequency changes if only insertion of Li-ion would occur based on the following equation combining the well know Sauerbrey equation ${ }^{40}$ with Faraday law:

$$
\Delta \mathrm{F}_{\text {Faraday }}=\frac{C_{\mathrm{f}} \cdot M \cdot q}{n \cdot \mathrm{F}},
$$

where $C_{\mathrm{f}}=56.6 \mathrm{~Hz} \mathrm{ug}^{-1} \mathrm{~cm}^{-2}$ is the mass sensitivity constant of the sensor, $M$ is the atomic mass of the inserted ion, $q$ is the charge, $n$ and $\mathrm{F}$ are the numbers of the transferred electrodes, and the Faraday constant, respectively. The calculated $\Delta f / n$ change (or mass change), which corresponds to the insertion/desertion of cations, was calculated based on the charge measured during cycling by using Faraday's law. The differences between the measured and calculated frequency change values are attributed to the co-insertion of water molecules as $\mathrm{Li}^{+}$ions move into the $\mathrm{Ti}_{3} \mathrm{C}_{2} \mathrm{~T}_{x}$ sheets.

\section{Details of the density functional theory (DFT) simulations}

DFT calculations were performed with the Vienna ab initio Simulation Package (VASP) ${ }^{41}$. The Perdew-Burke-Ernzerhof (PBE) functional of generalized gradient approximation (GGA) was employed for electron exchange correlation ${ }^{42}$. Projector augmented-wave (PAW) potentials were adopted for nuclei-electron interaction ${ }^{43}$. A plane-wave basis set with the kinetic energy cutoff of $500 \mathrm{eV}$ was utilized for the valence electrons. DFT-D3 method was employed to account for van der Waals interactions ${ }^{44}$. Supercells containing $12 \mathrm{Ti}_{3} \mathrm{C}_{2} \mathrm{O}_{2}$ formula units were adopted to model 
MXene with different interfacial compositions. A $k$-point mesh of $2 \times 2 \times 2$ was used for sampling the Brillouin zone. The convergence criteria were set to $10^{-5} \mathrm{eV}$ in energy and $0.01 \mathrm{eV} / \AA \AA$ in force. To determine the $d$-spacing, we optimized the structure as a function of the $c$ lattice parameter. The total energy $v s c$ was then fitted by a cubic polynomial function and the minimum of the fitted function was determined as the optimal $d$-spacing. Based on the experimental accumulated charge through the cathodic scan of a three-electrode Swagelok cell, the number of inserted $\mathrm{Li}^{+}$per unit of $\mathrm{Ti}_{3} \mathrm{C}_{2} \mathrm{~T}_{x}$ was estimated (assuming each inserted $\mathrm{Li}^{+}$contributed to one charge).

The Li differential insertion energy can be obtained as:

$$
\begin{aligned}
\Delta G= & E\left[\mathrm{Ti}_{3} \mathrm{C}_{2} \mathrm{O}_{2} \cdot y_{\text {final }} \mathrm{H}_{2} \mathrm{O} \cdot x_{\text {final }} \mathrm{Li}\right]-E\left[\mathrm{Ti}_{3} \mathrm{C}_{2} \mathrm{O}_{2} \cdot y_{\text {initial }} \mathrm{H}_{2} \mathrm{O} \cdot x_{\text {initial }} \mathrm{Li}\right] \\
& -\left(y_{\text {final }}-y_{\text {initial }}\right) \mu\left[\mathrm{H}_{2} \mathrm{O}\right]-\left(x_{\text {final }}-x_{\text {initial }}\right) E[\mathrm{Li}] .
\end{aligned}
$$

Here we assume $\mu\left[\mathrm{H}_{2} \mathrm{O}\right]$ of liquid water is equal to the $\mu\left[\mathrm{H}_{2} \mathrm{O}\right]$ of the water vapor at saturated vapor pressure. ${ }^{45,} 46$ The corresponding intercalation voltage referenced to standard lithium electrode was calculated as

$$
V=-\Delta G / \mathrm{e},
$$

and then converted to $\mathrm{Ag} / \mathrm{AgCl}$ electrode referenced according to standard electrode potential database.

\section{Electrochemical tests}

\section{Electrode and cell preparation}

The vacuum-filtered $\mathrm{Ti}_{3} \mathrm{C}_{2}$ films, the annealed films and the templated MXene films were used directly as the electrode material. The mass loading of all films used in this study is in the 
range of $0.7-1.0 \mathrm{mg} / \mathrm{cm}^{2}$. The YP-50 activated carbon powder (Kuraray, Japan) was mixed with 5\% polytetrafluoroethylene (Millipore-Sigma) in ethanol, rolled into a freestanding film and cut into a disk-shaped electrode. The YP-50 activated carbon electrode was used as the overcapacitive counter electrode for the 3-electrode cell with the MXene film as the working electrode. YP-50 activated carbon with a mass loading of $1 \mathrm{mg} / \mathrm{cm}^{2}$ is also used as the working electrode in the 3electrode cell in the $19.2 \mathrm{~m} \mathrm{LiBr}$ electrolyte.

In a Swagelok cell, glassy carbon was used as the current collector, the silver wire was reference electrode in all the neutral aqueous electrolyte. The $\mathrm{Ag} / \mathrm{AgCl}\left(3.5 \mathrm{M} \mathrm{KCl}, 25{ }^{\circ} \mathrm{C}\right)$ reference electrode was the reference electrode for the $\mathrm{H}_{2} \mathrm{SO}_{4}$ electrolyte, and the potential was converted to vs Ag wire in the same electrolyte in the Figure 1a. For a three-electrode assembly, one working electrode (MXene or YP-50 electrode) and one overcapacitive counter electrode (YP50) were separated by the Celgard separator. For a two-electrode cell, two MXene films were used as positive and negative electrodes, and a silver wire was added as an additional reference to monitor the potential change of each electrode. The properties of the electrolytes used in this study are summarized in the Table S1. After the electrolyte was added, the cell was capped by a rubber plug and stabilized for at least $6 \mathrm{~h}$ before the electrochemical tests.

\section{Electrochemical tests and calculations}

The electrochemical performance was tested on a Biologic VMP3 potentiostat. Chronoamperometry tests were performed by applying a constant voltage $(0.2,0.4,0.6$ and $0.8 \mathrm{~V}$ $v s$ Ag wire) to the three-electrode cell and recording the response of the current density with time. Cyclic voltammetry (CV) was tested from scan rate of $2 \mathrm{mV} / \mathrm{s}$ to $10,000 \mathrm{mV} / \mathrm{s}$, and galvanostatic charge-discharge $(\mathrm{GCD})$ test was performed at current densities from 1 to $10 \mathrm{~A} / \mathrm{g}$. The impedance 
spectroscopy was tested in a range of $10 \mathrm{mHz}$ to $300 \mathrm{kHz}$ under OCV and biased potentials within the maximum applied voltage (each potential was held for 10 min before the test).

The gravimetric capacitance $\left(C_{\mathrm{g}}\right)$ was calculated from the anodic scan of $\mathrm{CV}$ curve based on:

$$
C_{\mathrm{g}}=\frac{\int i \cdot \mathrm{d} t}{m \cdot V},
$$

where, $i$ is the current changed by time $t$ and $V$ is the voltage window of the CV scan. $m$ is the mass of the active material on the working electrode for three-electrode cell and is the mass of active material on both electrodes for a two-electrode cell. The volumetric capacitance of full cell was calculated based on $C_{\mathrm{v}}=C_{\mathrm{g}} \times \rho_{\text {film }}$ (The density of the electrode).

The energy density $(E)$ of the full cell were estimated based on:

$$
E_{\mathrm{g}}=\frac{\int V \cdot i \cdot \mathrm{d} t}{m_{\text {total }}},
$$

where voltage $V$ and current $i$ are the function of time $t$, and $m_{\text {total }}$ is mass of both electrodes. The average power density was further evaluated based on $P=E / \Delta t$, where $\Delta t$ is the discharge time.

\section{ASSOCIATED CONTENT}

Supporting Information. The following files are available free of charge. Supplementary figures S1-S18 and Tables S1-S2 (PDF)

AUTHOR INFORMATION

Corresponding Author 
Correspondence should be addressed to Yury Gogotsi (gogotsi@drexel.edu)

\section{Author Contributions}

X.-H.W. and Y.G. initiated the project, led the collaborations, and wrote the manuscript. T.S.M. synthesized all MXenes. X.-H.W., T.S.M., W.-Y.T., N. S., H.S., and D.Z. conducted electrochemical tests. Y.S. performed the DFT simulation under the supervision of D. -E.J. AFM was performed by W.-Y.T. and N.B. EQCM was conducted by N.S and F.M. H.S. performed the in situ XRD measurement. D.Z. and K.H. performed UV-vis and XPS, respectively. All authors contributed to the writing of the manuscript under supervision from P.S. and Y.G.

\section{Notes}

The authors declare no competing financial interest.

\section{ACKNOWLEDGMENT}

This research was sponsored by the Fluid Interface Reactions, Structures and Transport (FIRST) Center, an Energy Frontier Research Center funded by the US Department of Energy, Office of Science and Office of Basic Energy Sciences. Operando AFM measurements were performed and supported at the Center for Nanophase Materials Sciences (CNMS) in Oak Ridge National Laboratory, which is a DOE Office of Science user facility. The authors also acknowledge K. Li, C. Shuck and J. Tang (all, Drexel University) for assistance with SEM, ex-situ XRD and Raman analyses.

\section{REFERENCES}


1. Pomerantseva, E.; Bonaccorso, F.; Feng, X.; Cui, Y.; Gogotsi, Y., Energy storage: The future enabled by nanomaterials. Science 2019, 366 (6468).

2. Simon, P.; Gogotsi, Y., Perspectives for electrochemical capacitors and related devices. Nat. Mater. 2020, 19 (11), 1151-1163.

3. Mathis, T. S.; Kurra, N.; Wang, X.; Pinto, D.; Simon, P.; Gogotsi, Y., Energy storage data reporting in perspective-guidelines for interpreting the performance of electrochemical energy storage systems. Adv. Energy Mater. 2019, 9 (39), 1902007.

4. Brousse, T.; Bélanger, D.; Long, J. W., To be or not to be pseudocapacitive. J. Electrochem. Soc. 2015, 162 (5), A5185-A5189.

5. Lukatskaya, M. R.; Kota, S.; Lin, Z.; Zhao, M.-Q.; Shpigel, N.; Levi, M. D.; Halim, J.; Taberna, P.-L.; Barsoum, M. W.; Simon, P., Ultra-high-rate pseudocapacitive energy storage in two-dimensional transition metal carbides. Nat. Energy 2017, 2 (8), 1-6.

6. Xia, Y.; Mathis, T. S.; Zhao, M.-Q.; Anasori, B.; Dang, A.; Zhou, Z.; Cho, H.; Gogotsi, Y.; Yang, S., Thickness-independent capacitance of vertically aligned liquid-crystalline MXenes. Nature 2018, 557 (7705), 409-412.

7. Augustyn, V.; Come, J.; Lowe, M. A.; Kim, J. W.; Taberna, P.-L.; Tolbert, S. H.; Abruña, H. D.; Simon, P.; Dunn, B., High-rate electrochemical energy storage through $\mathrm{Li}^{+}$intercalation pseudocapacitance. Nat. Mater. 2013, 12 (6), 518-522.

8. Li, Y.; Shao, H.; Lin, Z.; Lu, J.; Liu, L.; Duployer, B.; Persson, P. O.; Eklund, P.; Hultman, L.; Li, M., A general Lewis acidic etching route for preparing MXenes with enhanced electrochemical performance in non-aqueous electrolyte. Nat. Mater. 2020, 1-6. 
9. Wang, X.; Mathis, T. S.; Li, K.; Lin, Z.; Vlcek, L.; Torita, T.; Osti, N. C.; Hatter, C.; Urbankowski, P.; Sarycheva, A., Influences from solvents on charge storage in titanium carbide MXenes. Nat. Energy 2019, 4 (3), 241-248.

10. Suo, L.; Borodin, O.; Gao, T.; Olguin, M.; Ho, J.; Fan, X.; Luo, C.; Wang, C.; Xu, K., "Water-in-salt" electrolyte enables high-voltage aqueous lithium-ion chemistries. Science 2015, 350 (6263), 938-943.

11. Anasori, B.; Lukatskaya, M. R.; Gogotsi, Y., 2D metal carbides and nitrides (MXenes) for energy storage. Nat. Rev. Mater. 2017, 2 (2), 1-17.

12. Lukatskaya, M. R.; Mashtalir, O.; Ren, C. E.; Dall’Agnese, Y.; Rozier, P.; Taberna, P. L.; Naguib, M.; Simon, P.; Barsoum, M. W.; Gogotsi, Y., Cation intercalation and high volumetric capacitance of two-dimensional titanium carbide. Science 2013, 341 (6153), 1502-1505.

13. Gao, Q.; Sun, W.; Ilani-Kashkouli, P.; Tselev, A.; Kent, P. R.; Kabengi, N.; Naguib, M.; Alhabeb, M.; Tsai, W.-Y.; Baddorf, A. P., Tracking ion intercalation into layered $\mathrm{Ti}_{3} \mathrm{C}_{2} \mathrm{MXene}$ films across length scales. Energy Environ. Sci. 2020, 13 (8), 2549-2558.

14. Kim, K.; Ando, Y.; Sugahara, A.; Ko, S.; Yamada, Y.; Otani, M.; Okubo, M.; Yamada, A., Dense charge accumulation in MXene with a hydrate-melt electrolyte. Chem. Mater. 2019, 31 (14), 5190-5196.

15. Kim, K.; Okubo, M.; Yamada, A., Interfacial dissociation of contact-ion-pair on MXene electrodes in concentrated aqueous electrolytes. J. Electrochem. Soc. 2019, 166 (15), A3739.

16. Wang, B.; Xie, Y.; Liu, T.; Luo, H.; Wang, B.; Wang, C.; Wang, L.; Wang, D.; Dou, S.; Zhou, Y., $\mathrm{LiFePO}_{4}$ quantum-dots composite synthesized by a general microreactor strategy for ultra-high-rate lithium ion batteries. Nano Energy 2017, 42, 363-372. 
17. Fleischmann, S.; Mitchell, J. B.; Wang, R.; Zhan, C.; Jiang, D.-e.; Presser, V.; Augustyn, V., Pseudocapacitance: from fundamental understanding to high power energy storage materials. Chem. Rev. 2020, 120 (14), 6738-6782.

18. Liu, W.; Yi, H.; Zheng, Q.; Li, X.; Zhang, H., Y-Doped $\mathrm{Na}_{3} \mathrm{~V}_{2}\left(\mathrm{PO}_{4}\right)_{2} \mathrm{~F}_{3}$ compounds for sodium ion battery cathodes: electrochemical performance and analysis of kinetic properties. $J$. Mater. Chem. A 2017, 5 (22), 10928-10935.

19. Tsai, W.-Y.; Wang, R.; Boyd, S.; Augustyn, V.; Balke, N., Probing local electrochemistry via mechanical cyclic voltammetry curves. Nano Energy 2020, 81, 105592.

20. Li, J.; Wang, X.; Sun, W.; Maleski, K.; Shuck, C.; Li, K.; Urbankowski, P.; Hantanasirisakul, K.; Wang, X.; Kent, P., Intercalation induced reversible electrochromic behavior of two-dimensional $\mathrm{Ti}_{3} \mathrm{C}_{2} \mathrm{~T}_{x}$ MXene in organic electrolytes. ChemElectroChem $\mathbf{2 0 2 0}$.

21. Sugahara, A.; Ando, Y.; Kajiyama, S.; Yazawa, K.; Gotoh, K.; Otani, M.; Okubo, M.; Yamada, A., Negative dielectric constant of water confined in nanosheets. Nat. Commun. 2019, $10(1), 1-7$.

22. Mu, X.; Wang, D.; Du, F.; Chen, G.; Wang, C.; Wei, Y.; Gogotsi, Y.; Gao, Y.; Dall'Agnese, Y., Revealing the pseudo-intercalation charge storage mechanism of MXenes in acidic electrolyte. Adv. Funct. Mater. 2019, 29 (29), 1902953.

23. Shao, H.; Xu, K.; Wu, Y.-C.; Iadecola, A.; Liu, L.; Ma, H.; Qu, L.; Raymundo-Pinero, E.; Zhu, J.; Lin, Z., Unraveling the charge storage mechanism of $\mathrm{Ti}_{3} \mathrm{C}_{2} \mathrm{~T}_{x}$ MXene electrode in acidic electrolyte. ACS Energy Lett. 2020, 5 (9), 2873-2880.

24. Lukatskaya, M. R.; Bak, S. M.; Yu, X.; Yang, X. Q.; Barsoum, M. W.; Gogotsi, Y., Probing the mechanism of high capacitance in 2D titanium carbide using in situ X-ray absorption spectroscopy. Adv. Energy Mater. 2015, 5 (15), 1500589. 
25. Ando, Y.; Okubo, M.; Yamada, A.; Otani, M., Capacitive versus pseudocapacitive storage in MXene. Adv. Funct. Mater. 2020, 2000820.

26. Shpigel, N.; Levi, M. D.; Sigalov, S.; Mathis, T. S.; Gogotsi, Y.; Aurbach, D., Direct assessment of nanoconfined water in $2 \mathrm{D} \mathrm{Ti}_{3} \mathrm{C}_{2}$ electrode interspaces by a surface acoustic technique. J. Am. Chem. Soc. 2018, 140 (28), 8910-8917.

27. Li, K.; Wang, X.; Wang, X.; Liang, M.; Nicolosi, V.; Xu, Y.; Gogotsi, Y., Allpseudocapacitive asymmetric MXene-carbon-conducting polymer supercapacitors. Nano Energy 2020, 75, 104971.

28. Peng, Y.-Y.; Akuzum, B.; Kurra, N.; Zhao, M.-Q.; Alhabeb, M.; Anasori, B.; Kumbur, E. C.; Alshareef, H. N.; Ger, M.-D.; Gogotsi, Y., All-MXene (2D titanium carbide) solid-state microsupercapacitors for on-chip energy storage. Energy Environ. Sci. 2016, 9 (9), 2847-2854.

29. Pinto, D.; Anasori, B.; Avireddy, H.; Shuck, C. E.; Hantanasirisakul, K.; Deysher, G.; Morante, J. R.; Porzio, W.; Alshareef, H. N.; Gogotsi, Y., Synthesis and electrochemical properties of 2D molybdenum vanadium carbides-solid solution MXenes. J. Mater. Chem. A 2020, 8 (18), 8957-8968.

30. Schütter, C.; Pohlmann, S.; Balducci, A., Industrial requirements of materials for electrical double layer capacitors: impact on current and future applications. Adv. Energy Mater. 2019, 9 (25), 1900334.

31. Mathis, T. S.; Maleski, K.; Goad, A.; Sarycheva, A.; Anayee, M.; Foucher, A. C.; Hantanasirisakul, K.; Shuck, C. E.; Stach, E. A.; Gogotsi, Y., Modified MAX phase synthesis for environmentally stable and highly conductive $\mathrm{Ti}_{3} \mathrm{C}_{2}$ MXene. ACS Nano 2021, 15 (4), 6420-6429.

32. Cai, G.; Ciou, J.-H.; Liu, Y.; Jiang, Y.; Lee, P. S., Leaf-inspired multiresponsive MXenebased actuator for programmable smart devices. $S c i . A d v$. 2019, 5 (7), eaaw7956. 
33. Wen, B.; Cao, M.; Lu, M.; Cao, W.; Shi, H.; Liu, J.; Wang, X.; Jin, H.; Fang, X.; Wang, W., Reduced graphene oxides: light-weight and high-efficiency electromagnetic interference shielding at elevated temperatures. Adv. Mater. 2014, 26 (21), 3484-3489.

34. Cao, M.; Wang, X.; Cao, W.; Fang, X.; Wen, B.; Yuan, J., Thermally driven transport and relaxation switching self-powered electromagnetic energy conversion. Small 2018, 14 (29), 1800987.

35. Iqbal, A.; Shahzad, F.; Hantanasirisakul, K.; Kim, M.-K.; Kwon, J.; Hong, J.; Kim, H.; Kim, D.; Gogotsi, Y.; Koo, C. M., Anomalous absorption of electromagnetic waves by 2D transition metal carbonitride $\mathrm{Ti}_{3} \mathrm{CNT}_{\mathrm{x}}$ (MXene). Science 2020, 369 (6502), 446-450.

36. Mathis, T.; Maleski, M.; Goad, A.; Sarycheva, A.; Anayee, M.; Foucher, A. C.; Hantanasirisakul, K.; Stach, E.; Gogotsi, Y., Modified MAX Phase Synthesis for Environmentally Stable and Highly Conductive $\mathrm{Ti}_{3} \mathrm{C}_{2}$ MXene. ChemRxiv 2020.

37. Park, S. H.; Kim, J.; Lee, W.-E.; Byun, D.-J.; Kim, M. H., One-step synthesis of hollow dimpled polystyrene microparticles by dispersion polymerization. Langmuir 2017, 33 (9), 22752282.

38. Mu, X.; Wang, D.; Du, F.; Chen, G.; Wang, C.; Wei, Y.; Gogotsi, Y.; Gao, Y.; Dall'Agnese, Y., Revealing the pseudo-intercalation charge storage mechanism of MXenes in acidic electrolyte. Adv. Funct. Mater. 2019, 29 (29), 1902953.

39. Shpigel, N.; Levi, M. D.; Aurbach, D., EQCM-D technique for complex mechanical characterization of energy storage electrodes: Background and practical guide. Energy Storage Mater. 2019, 21, 399-413.

40. Sauerbrey, G., Verwendung von Schwingquarzen zur Wägung dünner Schichten und zur Mikrowägung. Z. Phys. 1959, 155 (2), 206-222. 
41. Kresse, G.; Furthmüller, J., Efficient iterative schemes for ab initio total-energy calculations using a plane-wave basis set. Phys. Rev. B 1996, 54 (16), 11169.

42. Perdew, J. P.; Burke, K.; Ernzerhof, M., Generalized gradient approximation made simple. Phys. Rev. Lett. 1996, 77 (18), 3865.

43. Blöchl, P. E., Projector augmented-wave method. Phys. Rev. B 1994, 50 (24), 17953.

44. Grimme, S.; Antony, J.; Ehrlich, S.; Krieg, H., A consistent and accurate ab initio parametrization of density functional dispersion correction (DFT-D) for the 94 elements H-Pu. $J$. Chem. Phys. 2010, 132 (15), 154104.

45. Peterson, A. A.; Abild-Pedersen, F.; Studt, F.; Rossmeisl, J.; Nørskov, J. K., How copper catalyzes the electroreduction of carbon dioxide into hydrocarbon fuels. Energy Environ. Sci. 2010, 3 (9), 1311-1315.

46. Gokcen, N. A., Vapor pressure of water above saturated lithium chloride solution. J. Am. Chem. Soc. 1951, 73 (8), 3789-3790. 